\title{
Expression of Concern: Influence of introducing various meteorological parameters to the Angström-Prescott model for estimation of global solar radiation
}

\author{
Kasra Mohammadi $^{1} \cdot$ Hossein Khorasanizadeh ${ }^{2} \cdot$ Shahaboddin Shamshirband ${ }^{3} \cdot$ Chong Wen Tong $^{4}$
}

Published online: 19 December 2018

๑) Springer-Verlag GmbH Germany, part of Springer Nature 2018

\section{Expression of Concern: \\ Environ Earth Sci (2016) 75:219 \\ https://doi.org/10.1007/s12665-015-4871-z}

The Editors-in-Chief of Environmental Earth Sciences are issuing an editorial expression of concern to alert readers that this article (Mohammadi et al. 2016) shows substantial indication of irregularities in authorship during the submission process. The authors suggested peer reviewers whose identity was not possible to verify. This article contains overlap with Khorasanizadeh et al. (2013, 2014), Mohammadi et al. (2014), Shamshirband et al. (2016) (amongst others). All authors disagree with this editorial expression of concern.

The original article can be found online at https://doi.org/10.1007/ s12665-015-4871-z.

Shahaboddin Shamshirband

shamshirband@um.edu.my

Kasra Mohammadi

kmohammadi@umass.edu

Hossein Khorasanizadeh

khorasan@kashanu.ac.ir

1 Department of Mechanical and Industrial Engineering, University of Massachusetts, Amherst, MA 01003, USA

2 Faculty of Mechanical Engineering and Energy Research Institute, University of Kashan, Kashan, Iran

3 Department of Computer System and Technology, Faculty of Computer Science and Information Technology,

University of Malaya, 50603 Kuala Lumpur, Malaysia

4 Department of Mechanical Engineering, Faculty of Engineering, University of Malaya, 50603 Kuala Lumpur, Malaysia

\section{References}

Khorasanizadeh H, Mohammadi K (2013) Introducing the best model for predicting the monthly mean global solar radiation over six major cities of Iran. Energy 51:257-266. https://doi.org/10.1016/j. energy.2012.11.007

Khorasanizadeh H, Mohammadi K (2014) A statistical comparative study to demonstrate the merit of day of the year-based models for estimation of horizontal global solar radiation. Energy Convers Manag 87:37-47. https://doi.org/10.1016/j.encon man.2014.06.086

Mohammadi K, Shamshirband S, Anisi MH et al (2014) Support vector regression based prediction of global solar radiation on a horizontal surface. Energy Convers Manag 91:433-441. https://doi. org/10.1016/j.enconman.2014.12.015

Mohammadi K, Khorasanizadeh H, Shamshirband S et al (2016) Influence of introducing various meteorological parameters to the Angström-Prescott model for estimation of global solar radiation. Environ Earth Sci 75:219. https://doi.org/10.1007/s1266 5-015-4871-z

Shamshirband S, Mohammadi K, Tong CW et al (2016) A hybrid SVM-FFA method for prediction of monthly mean global solar radiation. Theor Appl Climatol 125:53. https://doi.org/10.1007/ s00704-015-1482-2

Publisher's Note Springer Nature remains neutral with regard to jurisdictional claims in published maps and institutional affiliations. 